\title{
A Synthesis on SWOT Analysis of Public Sector Healthcare Knowledge Management Information Systems in Pakistan
}

\author{
Arfan Arshad \\ Department of Information System \\ KICT, International Islamic University \\ Malaysia
}

\author{
Mohamad Fauzan Noordin \\ Department of Information System \\ KICT, International Islamic University \\ Malaysia
}

\author{
Roslina Bint Othman \\ Department of Library \& Information \\ System, KICT, International Islamic \\ University, Malaysia
}

\begin{abstract}
Healthcare is a community service sector and has been delivering its services for the betterment of civic health since its establishment at communal level. For working efficiently and effectively, this sector profoundly relies on correct and complete health information of people and a proficient integrated healthcare knowledge management information system (HKMIS) to manage this information. The performance of Healthcare organizations has significantly augmented by inception of Information and Communications Technology (ICT) in HKMIS in developed countries, but is yet to exhibit its full potential in developing countries specifically those with huge populations like Pakistan. An exploratory qualitative research methodology was adopted to conduct this study. The purpose and objective of this study was to determine and investigate the internal and external factors that influence the performance of HKMIS by performing SWOT analysis on two of the largest public-sector healthcare organizations of Pakistan. The findings of this study will certainly help authorities to devise methods of improvement in Pakistani HKMIS eventually paving ways towards a better and improved healthcare in the future.
\end{abstract}

Keywords-Healthcare; knowledge management; healthcare knowledge management information system; information and communications technology; SWOT analysis; internal and external factors; healthcare organizations

\section{INTRODUCTION: AN OVERVIEW}

Developing countries have always been under extreme pressure and facing challenges in providing community services to the public sector as healthcare being one of them to be mentioned. Specifically, nations like Pakistan having huge population (where more than $60 \%$ population is colonized in rural areas) face a great deal and variety of challenges related to healthcare systems and their effective implementation mainly due to limited resources and working capability [1].

Healthcare organizations now-a-days rely on healthy healthcare knowledge management information systems (HKMIS) to provide reliable data that report on health system performance [1]. Hence availability of relevant, timely and accurate information related to healthcare system performance is the key to successful strengthening of the healthcare systems [2]. Further, Information and Communications Technology (ICT) has been an important tool being used to expand the healthcare systems working capabilities beyond physical limits. Some of the examples in this respect are Telemedicine, E-Health, and Tele-pharmacy, etc. [3].

Now-a-days, healthcare management information systems are used to support the overall management of healthcare organization related to data and information about patient care, diseases, up-to performing resource management and knowledge management [6]. An advanced innovated and integrated form of these systems is known as Knowledge Management System (KMS). HKMIS are affected by a great variety of internal and external influential factors [26]. How well an HKMIS performs, depends on these influential factors and issues related to them [7]. A typical HKMIS architecture for clinic to large healthcare organization access application anytime from anywhere is shown in Fig. 1.

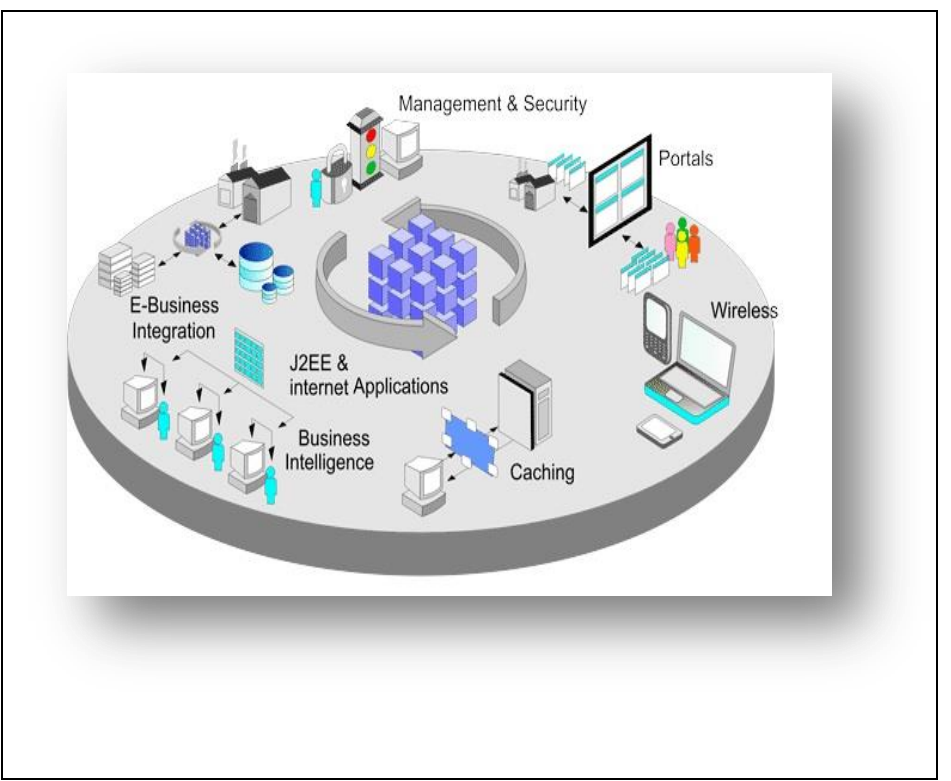

Fig. 1. A Typical HKMIS Framework Architecture Adapted from http://www.hospycare.com/technology.html.

A perfect HKMIS is basically triangulation of three professional disciplines named as Medicine, ICT and Management [4]. At times, the HKMIS have been evolved and taken different names as Hospital Information Systems, Clinical information systems, Hospital information 
management systems and Healthcare information systems etc, all exhibiting and serving the same purpose and objectives [5].

This study used a professional and scientific approach named as SWOT analysis to identify and determine these internal and external influential factors for evaluating the existing condition of HKMIS in public sector healthcare organizations of Pakistan. The research questions comprised of:

1) What is the condition of existing HKMIS implemented in public sector organizations of Pakistan?

2) What are the Strengths of the existing HKMIS under study?

3) What are the weaknesses and their possible influential factors that impact existing HKMIS?

4) What are the opportunities to improve the working capability and performance of public sector HKMIS?

5) What are the possible threats that may lead to failure of HKMIS?

\section{BACKGROUND AND LITERATURE REVIEW}

\section{A. History of Healthcare Computing}

Use of computers in healthcare is not a contemporary phenomenon. It's been more than six decades, since some of the major healthcare organizations started using computers for the processing of batch files of health related records [8]. During early 1950s, most of the major hospitals of G7 countries started using mainframe computers for routine data processing related to healthcare. Although it was very slow as compared to latest computing systems [9], [10].

The era starting from early 1960s through the mid 1970s experienced new emerging essence in healthcare computing. The performance of automated computing medical systems also improved considerably and it paved the path towards increased use and integration of computing systems into healthcare systems [9], [10]. The era of early 1980s was dedicated to computer miniaturization and drastic increase in processing power along with storage capacity. This helped many healthcare organizations round the globe to implement new healthcare management information systems (HMIS). This helped a lot to process massive and huge health data processing being fast and accurate [9], [10].

Later on, Innovation in networking and telecommunication systems during 1990s took healthcare computing systems i.e. HMIS further step ahead, enhancing them into integrated and distributed HMIS. This helped to reduce distance by introducing the innovative concepts of E-healthcare such as Tele-medicine, Tele-pharmacy, etc. The E-healthcare was further advanced to E-nursing systems, E-homecare systems, E-Clinical Decision Support Systems, Knowledge Based Systems and expert systems [9], [10].

\section{B. Healthcare Computing / HKMIS in Pakistan}

Due to its massive data creation and handling sensitive confidential information, healthcare is considered as an important industry now-a-days [29]. So, keeping in view the importance of healthcare data and its effective utilization, the Government of Pakistan considered revolutionizing the healthcare industry and changing from manual data processing to electronic data processing methods in early 1990s. In response to this need the Ministry of Health, Government of Pakistan, in collaboration with the provincial healthcare departments and international agencies developed a National Health Management Information Systems (HMIS) during 1990-93 [17]-[19].

An effort was instigated by the Basic Health Services Cell (now National HMIS Cell of Ministry of Health, Government of Pakistan) to establish a countrywide HMIS facility in 1990s keeping in view the importance of management information systems as an essential tool required for improved performance and quality of working of healthcare organizations [30]. This effort was supported by significant Provincial Health Departments also. The initiative was financially and technically supported by international agencies like USAID, UNICEF and WHO also [31]. The objective was to provide support to tactical and operative managers in decision making process [17]-[19].

Further, the HMIS was institutionalized in all the provincial healthcare headquarters of the country by the help of Family Health Projects initiated by World Bank support in mid 1990s [32]. As per reports produced by Ministry of Healthcare, Government of Pakistan, more than $90 \%$ of the primary healthcare facilities of public sector account under this system which was implemented in a phased manner [17][19].

Subsequently, in 1994, the Government of Pakistan also developed a parallel community based information system (CBIS) under the National Program for Family Planning and Primary Healthcare (NPFP \& PHC). Additionally, some other several types of information systems related to Malaria, AIDS, and TB programs etc. are also running at the district levels but not fully integrated with National HMIS [17]-[19].

Despite all these efforts and initiatives, still a lot more is to be done in public sector HMIS to improve the performance and provision of quality healthcare facilities. This includes processing of collective information and data at centralized data processing facility, improvement in data quality, data collection methods, knowledge management, knowledge innovation and sharing, availability of summarized and scrutinized information to establish effective plans and assessment of healthcare services etc. Currently, reports generated by the facility based HMIS receives low priority, monitoring is poor and facility staff looks upon HMIS as an additional workload [20], [21].

The scope of the current HMIS is however, limited to the Primary Level healthcare facilities only and no data from inpatient/hospital, private care facilities or from the health facilities other than Provincial Health Departments are captured [22], [25].

\section{An Introduction to SWOT Analysis}

Every organization requires continuous improvements in its day to day processes for better performance and excellent quality of working [27]. This can be done if all the factors that influence the working of the organization are properly identified and defined [11]. Such factors are divided into 
internal factors (Strengths \& Weaknesses) and external factors (Opportunities \& Threats) [28]. The assessment and evaluation of these factors is done by using an exploratory scientific technique named as SWOT analysis. So, SWOT analysis can be defined as:

"SWOT Analysis is an examination and evaluation of an organization's internal strengths and weaknesses, its opportunities for growth and improvements and the threats the external environment poses to its survival and working [11]."

The definition can be summarized and exhibited in a matrix as shown in Fig. 2.

The internal factors are considered relatively controllable and can be manipulated by organization itself. On the contrary, the external factors are somewhat out of the control of the organization (may be controllable up-to some extent) and imposed by the environment in which the organization operates [12]. The SWOT analysis matrix illustrated in Fig. 2 clearly explains that (if it is performed realistically and unbiased) an organization must strive hard to improve the strengths and opportunities that are helpful towards attaining its objectives and goals. While on the other side, an organization must strive hard to eradicate its weaknesses and threats that hinder its performance and quality of working The key to success while performing SWOT analysis is to be honest, neutral, impartial and realistic [11].

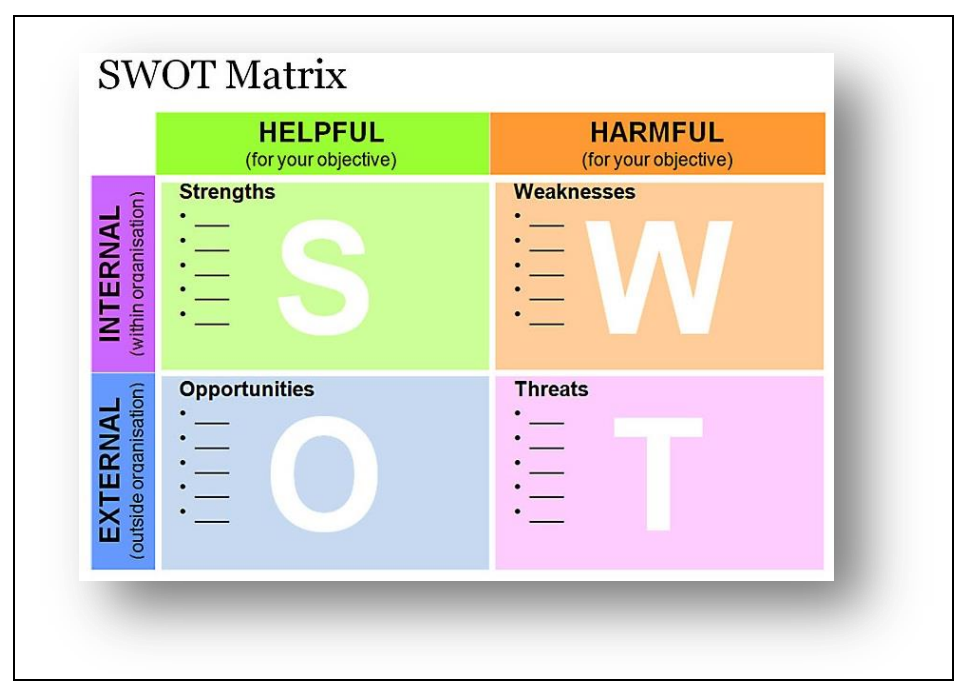

Fig. 2. SWOT Analysis Matrix Diagram - Adapted from "www.BusinessDocs.co.uk".

\section{SWOT Analysis: As a Process}

SWOT analysis is a preliminary exploratory tool that helps the organizations to investigate and evaluate their internal and external environment and the related influential factors. This tool helps the organization in their decision making process for taking steps that improve and increase the organizational performance and capability of quality working [13].

SWOT analysis can be divided into following four steps:

Step 1: The first step is used to identify, collect and analyze key data about the organization that may be related to working environment of the organization, community health status, funding resources, existing medical and computer technology along with demographic information of the population [13], [14].

Step 2: In second step the collected data is sorted and categorized according to strengths, weaknesses, opportunities and threats that influence the organizational working capability [13], [14].

Step 3: The third step is used to develop a SWOT matrix for each of the business alternative that is being considered to be likely a potential substitute or a better option [13], [14].

Step 4: The fourth step hence assists in decision making process. It helps the organization to integrate the findings and results of SWOT analysis with the decision making process for establishing and determining the best business alternative that best fits for the organizational strategic plans [13], [14].

\section{SWOT ANALYSIS IN HEALTHCARE}

SWOT analysis and evaluation technique was initially intended to present an overall systematic analysis of businesses that were related to organizations other than healthcare, but it has proven its usefulness and advantages in healthcare organizations as well. Recent years have experienced its increased use and great impact in healthcare industry [15]. It is pertinent that healthcare organizations also require improvement and innovation for increased performance, quality and optimum functionality. For this purpose, progressive adjustments and up-gradations are a necessity to acquire. To identify areas for improvements, SWOT analysis has been a helpful and successful tool that was ignored by healthcare organizations for many years [16].

The sorting and categorization of organizational data in Healthcare systems can be illustrated as under:

\section{A. Strengths}

Strengths are those internal factors that support and illustrate extraordinary performance of a healthcare organization e.g. extra ordinary IT infrastructure, highly qualified and experienced healthcare professionals, state of the art equipments, excellent services, etc. [13], [14].

\section{B. Weaknesses}

On the contrary, weaknesses are those internal factors that hinder the working capability and negatively affect the performance of a healthcare organization. They can be mismanagement of resources, lack of financial resources, incompetent healthcare professionals, outdated equipments, etc. [13], [14].

\section{Opportunities}

Opportunities are those factors that are external to healthcare organizations. They provide initiatives for improvements. Examples include collaborations with other organizations for better services, plans for better organization and management, new funding programs for better IT infrastructure, effective training and informative programs for community development, etc. [13], [14]. 


\section{Threats}

Threats are those external factors which are considered to be potential risks or dangers that could cause harm to the quality of working and performance of healthcare organizations. Economic instability, rapidly changing technology, budget deficits, un-necessary political intervention, and political insecurity are some of the related examples [13], [14].

\section{OBJECTIVES OF THE STUDY}

1) To perform a comprehensive and in-depth overall analysis of existing healthcare management information systems implemented in public sector organizations of Pakistan.

2) To identify and define Strengths of the existing HKMIS under study.

3) To evaluate weaknesses and their possible influential factors.

4) To discover better opportunities to improve the working capability and performance of public sector HKMIS.

5) To identify and evaluate the possible threats that may lead to failure of HKMIS.

\section{Methodology AND ApPROACH AdOPTED}

This cross sectional study was conducted in two famous and most visited healthcare public sector organizations present in Pakistan. An exploratory qualitative research methodology was adopted to conduct this study and a detailed analysis was performed on the data collected through detailed interviews, structured walkthroughs, observation, available forms and individual surveys at the end user level.

The study was also complemented and supported by a comprehensive methodological review of available literature and related data. Published and unpublished documents including government reports, peer review journals and other literature such as local journals were also a source of information for this study. The analysis was helped by discussion during interviews with the experts in the relevant field including government, stakeholder agencies and public sector healthcare specialists.

\section{The Case Study: Public Sector HealthCare ORGANIZATIONS}

\section{A. Introduction}

This section provides an excerpt of information from a case study conducted on two government hospitals (A \& Bpseudonym used to ensure confidentiality) in one of the major provincial capital city in Pakistan. These were one of the largest and oldest public healthcare organizations governed and controlled by the local government and comprising of more than 2000 beds collectively. Hospital "A" employs 1025 healthcare professionals with a total count of 1800 employees and staff in its 36 departments and is one of the oldest public sector healthcare organizations in Southeast Asia. Hospital B employs 1225 healthcare professionals with a total count of 2100 employees and staff in its 32 departments with its roots being older than 70 years. The hospitals seem to be overcrowded with a significant number of in-patients (A>30000, B>25000 per year) and out-patients $(A>1000000$, B $>900000$ per year).

\section{B. Conduction of Case Study}

The case study was conducted to obtain an account of information on practical grounds related to existence and implementation of HKMIS in the top and famous public sector Pakistani healthcare organizations. The researchers collected data and information for their study by help of generalized interviews, structured walkthroughs, existing document reviews and self observations. A substantial number of people including healthcare professionals, IT staff, support staff and some educated patients were met to dig out the information. The interviews and data collection objectives of the authors were generally based upon the following major domains and points:

- Know how about the terminologies "Knowledge" \& "Knowledge Management".

- Know how about the terminology "HKMIS" (Healthcare Knowledge Management Information System / Healthcare Management Information System)

- Know how about the importance of ICT in healthcare.

- Role of ICT in healthcare.

- Knowledge about working of HMIS / HKMIS.

- Benefits of a healthy HKMIS in healthcare.

- Financial and top management support for successful HKMIS implementation.

- Implementation of HKMIS processes in the organization.

- Role of HKMIS in strengthening the healthcare organization.

- Weaknesses of existing HKMIS.

- Opportunities and strategies to improve existing HKMIS

- Salient threats faced by HKMIS.

- Role of HKMIS in decision making.

- Best practices about HKMIS for patient care.

- Organizational and Technology infrastructure, etc.

\section{Findings and Results}

Compiling the findings and results was a hectic and tedious task. The data collected by the help of detailed interviews, discussions and individual surveys ended up with a great deal of variation and gaps among the answers produced by the tactical management, operational management, healthcare professionals and other individuals of the organizations. Nonetheless, the results of the discussions and observations revealed that most of the healthcare professionals, management personals, and other stakeholders involved in the research population from both the healthcare organizations do have some sort of understanding of the term 
HKMIS, its benefits and its role in improving the healthcare services.

Most of the time, the findings and results were supported by the help of data collected through self observations, structured walkthroughs and study of available forms and reports. Anyway, the available data was carefully compiled and was distributed and sorted in the four major categories according to the SWOT analysis tool.

Furthermore, it was established that both the healthcare organizations does not have a competent HKMIS implementation to support daily based healthcare activities with significant weaknesses, but it was also recognized that there are certain specific areas of opportunities available for improvements of-course keeping in mind the posed threats.

Tables 1 and 2 enlist the internal factors identified while conducting SWOT analysis on public sector healthcare organization's HKMIS.

TABLE I. SWOT ANALysis OF PUblic SeCtor HEALTHCARE INTERNAL FACTORS (STRENGTHS)

Internal Factors - Strengths identified:

1) Provision of improved healthcare services

2) Decrease in data and medical errors

3) Better and improved data storage

4) Better safeguarding and improved confidentiality of sensitive information

5) Better and fast communication between stakeholders

6) Increased and better cost savings

7) Improved access to accurate and relative information

8) Increased productivity of end users

9) Availability of timely data

10) Better and improved reporting

11) Reduced possibility of data loss

12) Improved quality and originality of documentation

13) Enhanced paperless environment

14) Solid and sound IT infrastructure

TABLE II. SWOT ANALYSIS OF PUBLIC SECTOR HEALTHCARE INTERNAL FACTORS (WEAKNESSES)

\section{Internal Factors - Weaknesses identified:}

\begin{tabular}{|l|ll|}
\hline & 1) & Shortage of competent staff \\
\cline { 2 - 3 } & 2) & Lack of specific and professional training programs \\
\cline { 2 - 3 } & 3) & Lack of top management commitment and seriousness \\
\hline \multirow{3}{*}{} &
\end{tabular}

\begin{tabular}{|ll|}
\hline 4$)$ & Lack of effective system integration \\
\hline 5) & Unprofessional reporting structure \\
\hline 6) & Fragmentation and disintegration of health information \\
\hline 7) & Lack of E-health services \\
\hline 8) & $\begin{array}{l}\text { Limited access to internet and collaborative tools / } \\
\text { applications }\end{array}$ \\
\hline 9) & $\begin{array}{l}\text { Lack of interest and professional ethics in learning new } \\
\text { systems }\end{array}$ \\
\hline 10) & Significant errors in recording healthcare data \\
\hline 11) & Lack of accountability and transparency \\
\hline 12) & Lack of sufficient hardware and software maintenance staff \\
\hline 13) & Lack of motivation or reward criteria \\
\hline 14) & Increased and high costs of IT adoption \\
\hline 15) & Limited or no interoperability between service providers \\
\hline
\end{tabular}

Tables 3 and 4 enlist the external factors identified while conducting SWOT analysis on public sector healthcare organization's HKMIS.

TABLE III. SWOT ANALYSIS OF PUBLIC SECTOR HEALTHCARE EXTERNAL FACTORS (OPPORTUNITIES)

External Factors - Opportunities Identified:

1) Improvement in reporting and data presentation capabilities

2) Improvement in quality of healthcare services

3) Effective and efficient resources utilization procedures

4) Improvement in patients trust and satisfaction

5) Encouragement in proactive healthcare practices

6) Public awareness and community support programs

7) Training programs and facilities

8) Unification and integration of Public and Private sector health records

9) Improved support for knowledge management and decision making

10) Productive, efficient and effective healthcare management

11) Better human resource management

12) Costing and budget analysis for enhanced funds utilization

13) Sufficient allocation of resources for supporting IT infrastructure

14) Internet availability and enhanced bandwidth 
TABLE IV. SWOT ANALYSIS OF PUBLIC SECTOR HEALTHCARE EXTERNAL FACTORS (THREATS)

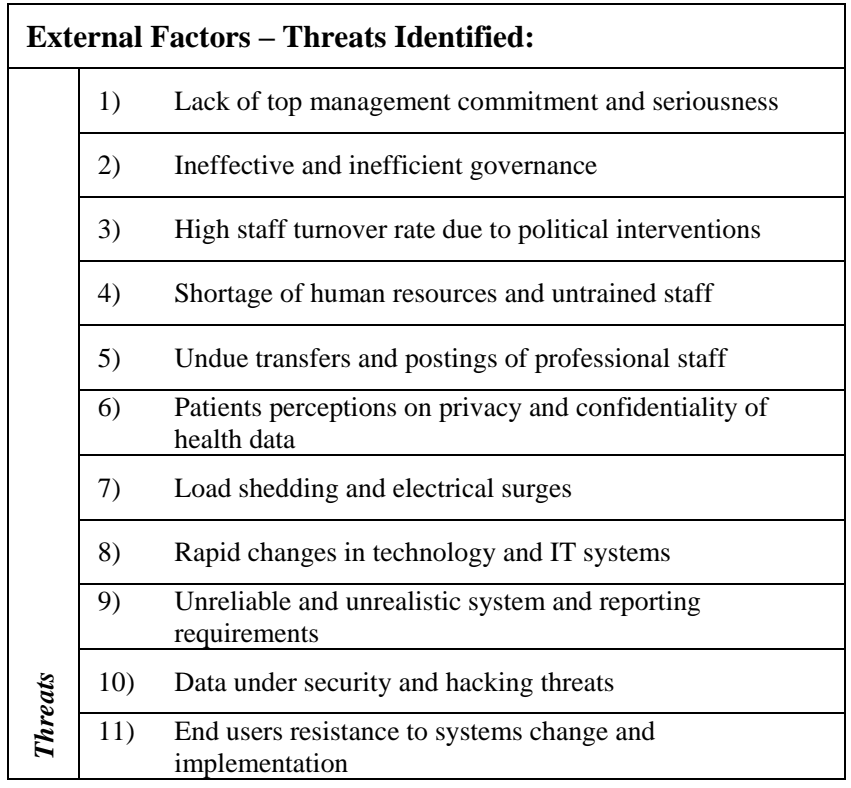

\section{DISCUSSION AND CONCLUSION}

There are no two opinions on the fact that ICT and healthy HKMIS have been a key factor for providing timely, accurate and reliable information for supporting decision making process in improving healthcare services in public as well as private sector healthcare organizations [23]. The working capability and performance of such systems can improve by dealing professionally with internal and external factors that influence them. This has a positive impact on quality of service, growth and sustainability of the healthcare programs and strategic plans induced by healthcare organizations [24].

On the other side, it is also important that HKMIS must be easy to use, flexible and easy to understand as well as must incorporate with user requirements. Public sector healthcare organizations face a drastic increase in patient visits every year due to constant increase in population of developing countries and deteriorating conditions of healthcare and non availability of healthy environment. So, HKMIS at public sector healthcare organization is under extreme constant pressure to deal with loads of healthcare data and information along with its processing and provision for decision making. These objectives can be attained in a better way by taking care of weaknesses and threats posed to the healthcare organizations. Further, taking benefit of prevailing opportunities also helps improvise the working capability and performance of the HKMIS.

This study performed a detailed SWOT analysis on public sector healthcare organizations of Pakistan and presented the facts and findings in detailed as well as summarized manner. An influential and healthy HKMIS is considered to be useful when it provides information that helps decision making effectively and efficiently.

For further research, each and every point identified and mentioned as strengths, weaknesses, opportunities and threats in public sector healthcare organizations of Pakistan, could be studied in depth and alternate solutions could be identified and implemented to cater them.

\section{REFERENCES}

[1] Hameed, Shafqat, Jawad Karamat, and Kashif Mehmood, "Effectual dynamics and prolific usage of knowledge management \& engineering in health care industry," Life Science Journal, vol. 9, issue 2, 2012.

[2] C. AbouZahr, and T. Boerma, "Health information systems: The foundations of public health," Bulletin of World Health Organization, vol. 83/8, pp. 578-583, August 2005.

[3] M. C. Azubuike, J. E. Ehiri, "Health information systems in developing countries: Benefits, problems, and prospects," Journal of the Royal Society for Promotion of Health, vol. 119, pp. 180-184, 1999.

[4] Hussain, Fehmida, and S. Ali Raza, "A knowledge management framework to operationalize experiential knowledge: mapping tacit medical knowledge with explicit practice guidelines," National Conference on Emerging Technologies, 2004.

[5] N. Mahmood, A. Burney, Z, Abbas, and K. Rizwan, "Data and knowledge management in designing healthcare information systems," International Journal of Computer Applications, vol. 50, no. 2, July 2012.

[6] A. Razzaque, and A. Jalal-Karim, "Conceptual healthcare knowledge management model for adaptability and interoperability of EHR," European, Mediterranean \& Middle Eastern Conference on Information Systems, 2010 (EMCIS2010), April 12-13 2010, Abu Dhabi, UAE

[7] S.C. Chong, and Y.S. Choi, "Critical Factors in the Successful Implementation of Knowledge management," Journal of Knowledge Management Practice, June 2005, [Electronic], available: http://www.tlainc.com/articl90.htm

[8] T. Lippeveld, R. Sauerborn, and C. Bodart, "Design and implementation of health management information systems," Geneva: World Health Organization, 2000.

[9] World Health Organization. 2008. "Health information systems, toolkit on monitoring health system strengthening," Geneva: WHO; 2008.

[10] World Health Organization. World Health Report. 2003. "Shaping the Future," Geneva: WHO; 2003.

[11] Z. Terzic, Z. Vukasinovic, V. Bjegovic-Mikanovi, V. Jovanovic, and R. Janicic, "SWOT analysis: The analytical method in the process of planning and its application in the development of orthopedic hospital department," Srpski Arhiv Za Celokupno Lekarstvo - Journals, vol. 138, pp. 473-479, 2010.

[12] M. Smith, S. Madon, A. Anifalaje, M. Lazarro-Malecela, and E. Michael, "Integrated Health Information Systems in Tanzania: experience and challenges," The Electronic Journal of Information Systems in Developing Countries, vol. 33, pp. 1-21, 2008.

[13] M.H. Marilyn, J. Nixon, "Exploring SWOT analysis - where are we now?: A review of academic research from the last decade", Journal of Strategy and Management, Vol. 3 Issue: 3, pp.215-251, doi: 10.1108/17554251011064837, 2010.

[14] J.D.H Wijngaarden, G.R.M.Scholten, and K.P.V Wijk, "Strategic analysis for health care organizations: the suitability of the SWOTanalysis," International Journal of Health Planning and Management, vol. 27, pp. 34-49, doi:10.1002/hpm.1032, 2012.

[15] M. Ali, and Y. Horikoshi, "Situation analysis of health management information system in Pakistan," Pakistan Journal of Medical Research, vol. 41, pp. 64-69, 2002.

[16] S. Nishtar, "The Gateway Paper: Health System in Pakistan - A way forward,' Islamabad, Pakistan: Pakistan's Health Policy Forum and Heart-file, 2006, Available from URL: http://www.heartfile.org/pdf/phpfGWP.Pdf

[17] Ministry of Health, Government of Pakistan. 1995. "Health Management Information System: National Feed Back Report September 1995," Primary Health Care Cell. Islamabad, 1995.

[18] Ministry of Health, Government of Pakistan, "Health Management Information System: National Feed Back Report 1996," Primary Health Care Cell. Islamabad, 1996. 
[19] Ministry of Health, Government of Pakistan, "Health management information system: National feedback report," September 1997-98: National MIS Cell, 1999.

[20] M.Q. Suleman, and M. Ali, "Pakistan's Health management information system: Health manager's perspectives," Journal of Pakistan Medical Association, vol. 59, pp.10-14, 2009.

[21] Hafeez, Z. Khan, K.M. Bile, R. Jooma, and M. Sheikh, "Pakistan human resources for health assessment," Eastern Mediterranean Health Journal, (16-Suppl), pp. 145-51, 2010.

[22] M.S. Qazi, and M. Ali, "Health Management Information System utilization in Pakistan: challenges, pitfalls and the way forward," Bioscience Trends, vol. 5, pp. 245-254, 2011.

[23] A. Rizwan, Bhutto and A. Maqsood, "Evaluating knowledge \& information-based healthcare system: A case study of DOW university of health sciences \& civil hospital Karachi," MS/MS152006ISR, 53 pages, January 2007.

[24] H. Lee, and B. Choi, "Knowledge management enablers, processes, and organizational performance: An integration and empirical examination," Journal of Management Information Systems, vol. 20(1), pp. 179-228, 2000 .

[25] M. Akram and F.J. Khan, "Health care services and government spending in Pakistan,” PIDE Working Papers, 2007.
[26] V.S. Anantatmula, and S.Kanungo, "Modeling enablers for successful KM implementation," Proceedings of the 40th Hawaii International Conference on System Sciences, 2007.

[27] M.F. Noordin, R. Othman, and N.A. Zakaria, "Peopleware and heartware - The philosophy of knowledge management, research and innovation in information systems (ICRIIS)," International Conference on 23-24 Nov. 2011.

[28] S.Y.S. Danesh, N.S. Rad, S.N. Mobasher, and M.M.S. Danesh, "The Investigation of Mutual Relations of Success Factors of Knowledge Management in Project-Centered Organizations," Journal of Basic and Applied Scientific Research, vol. 2, no. 4, pp. 3888-3896, 2012.

[29] WHO Report of the Health System Review Mission - Pakistan, Available from URL:http://gis.emro.who.int/HealthSystemObservatory/PDF/HealthSyst emReviewMission

[30] Ministry of Health, Government of Pakistan, "National Health Management Information System (HMIS): An Overview," http://www.pakistan.gov.pk/divisions/ContentInfo.jsp?DivID=25\&cPath =254_260\&ContentID=1635

[31] Government of Pakistan, "Pakistan Bureau of Statistics. Statistics Division," National Health Accounts Pakistan, 2009-10. Available from URL: www.pbs.gov.pk/content/nationalhealthaccountspakistan200910.

[32] Government of Pakistan, "Survey of private medical, dental and other health services. Islamabad, Pakistan," Federal Bureau of Statistics, 2001. 